\title{
Health Literacy in Younger Age Groups: Health Care Perceptions: Informed People Will Be More Prepared People
}

\author{
Cecília Nunes ${ }^{1}$, Cristina Vaz de Almeida², Célia Belim ${ }^{3}$ \\ ${ }^{1}$ Health Literacy Specialist (ISPA), Lisbon, Portugal \\ ${ }^{2}$ ISCSP, Lisbon, Portugal \\ ${ }^{3}$ ISCSP-U, Lisbon, Portugal \\ Email: cecilnunes@gmail.com
}

How to cite this paper: Nunes, C., de Almeida, C.V. and Belim, C. (2020) Health Literacy in Younger Age Groups: Health Care Perceptions: Informed People Will Be More Prepared People. Open Access Library Journal, 7: e6187.

https://doi.org/10.4236/oalib.1106187

Received: February 25, 2020

Accepted: March 17, 2020

Published: March 20, 2020

Copyright $\odot 2020$ by author(s) and Open Access Library Inc.

This work is licensed under the Creative Commons Attribution International License (CC BY 4.0).

http://creativecommons.org/licenses/by/4.0/

\begin{abstract}
Background: Young people and adolescents are increasingly using digital platforms for various purposes, including health aspects, which is not linear about whether they consider health information important or understand it. Objectives: Exploratory study with 51 individuals aged 17 to 25 years to ascertain their perception of health issues. Methodology: For this study, a 10-question questionnaire survey was elaborated and distributed online via the Facebook Social Network to 51 male and female adolescents, aged 17 to 25, living in the Greater Lisbon area, college students. Conclusions and Relevance: Young people want to know about their health, but feel that they should do this research by themselves. On the other hand, health information research and using skills demonstrate a failure in both access to reliable information and processing and understanding.
\end{abstract}

\section{Subject Areas}

Global Health, Nursing, Public Health

\section{Keywords}

Health Communication, Internet, Teenagers, Young, Health Literacy

\section{Introduction}

Low literacy and illiteracy in health is very frequent and affects health significantly, in a "silent epidemic" of current societies [1]. Quenzel et al. [2], demonstrate the intrinsic link of literacy to health behaviors, with increasing inequalities among lower literate youth [2]. 
The term "literacy" is a neologism created by the Organization for Economic Cooperation and Development [3] for a broader sense than "literacy". If the concept of literacy translates the act of teaching and learning (reading, writing and calculating), literacy translates the ability to use these skills (taught and learned) in everyday practice [3].

The concept was adapted to health by Simonds in 1974, which kept it linked to education, proposing the creation of curricular structures at different levels of education, establishing minimum health literacy standards, and local support when these standards were not met [4]. Evolution came to determine a less school-centered perspective. Health literacy today is understood as the degree to which individuals have the ability to obtain, process and understand basic health information, as well as the use of necessary services to make appropriate decisions [5].

A literate population is better able to deal with health and disease processes, both preventively and therapeutically, and better able to live an autonomous and functional life [6]. Literacy acts as a key factor in social equity by allowing access to otherwise missed health opportunities, maximizing each one's productive potential [7]. This outlook follows life-long, but it is particularly important at younger ages when the impact of individual options multiplies over time.

The youth population is defined by the World Health Organization (WHO) as the group of individuals aged between 10 and 24, with the designation of adolescents between 10 and 19 years old and young people between 15 and 24 years old years. It is at this stage that behaviors and attitudes are consolidated that can compromise, for better and for worse, future health [8]. It is important to ensure training for the most appropriate options that can guarantee a healthy life. Currently, the main source of information for young people is the internet [9] but we know that despite ease of access, young people lack eHealth literacy skills, with difficulty in assessing and processing health information digitally [10]. It is the difference between whether taking advice from health professionals or taking the medication they need [11], assuming it to be a decisive factor in the quality of medical care that many people receive [12].

It is interesting to understand how young people access health information and how useful it is in order to improve strategies for effective empowerment.

\section{Methods}

This is an exploratory cross-sectional study, for convenience, applied to 51 university students between $7^{\text {th }}$ of May and $5^{\text {th }}$ of June 2018. The convenience sample $(\mathrm{N}=51)$ includes individuals aged between 17 and 25 years old, male and female, living in the greater Lisbon area. The Inclusion criteria was being an university student and exclusion criteria was to be a non-university student. A total of $74.5 \%$ of young people are aged from 17 to 20 and $25.5 \%$ from 21 to 25 years.

The questionnaire survey was disseminated online on social networks (via face book) and consisted of 10 closed questions (Table 1 and Table 2). Because it is a 
Table 1. Characterization of the questionnaire.

\begin{tabular}{cl}
\hline Number of Questions & \multicolumn{1}{c}{10,1 of them socio-demographic } \\
\hline & In the field of health literacy: \\
& Access health information p 4) \\
Use of health services & Understanding health information (p 8) \\
Categories & Health promotion regarding healthy lifestyles \\
& Each question allowed a required option \\
Scale & Online, facebook \\
Dissemination & 7th May-5th June 2018 \\
\hline
\end{tabular}

Source: Authors.

Table 2. The 10 questions.

Questions from questionnaire

(P1) How old are you?

(P2) Are you a student?

(P3) On your opinion, what is to be healthy?

(P4) How often do you visit a Doctor?

(P5) What institutions or health related services you know?

(P6) Do you feel the need to have a doctor giving you advise about your health?

(P7) Do you use to read about health? If so, which means do you prefer?

(P8) What is your opinion about medical information available for young people?

(P9) Of the following areas, which one deserves your most attention (which you care most about)?

(P10) Do you have direct family members (parents, siblings, uncles, cousins) who are health professionals? If so, do you feel that this person/s has an influence on your general health knowledge?

Source: Authors.

very small sample and for convenience, there are limitations on replicability of results to similar populations. However the answers to the questionnaire given by this population bring some interesting records to develop later.

The language used in the questionnaire was intentionally clear, simple to be assertive [13] [14], familiar, with 1st person treatment, straightforward questions and simple language to meet the guidelines plain writing which means clear, concise, well-organized writing that follows other best practices appropriate for the subject or field and the public and which advises a language at the 8th grade level [15].

Health-related questions are focus on: 1) How they consider and care about their health; 2) What they know about health, focusing on 2 areas of health literacy, associated with knowledge (P7), understanding (P9) and use of information (P7).

The method applied was qualitative, based on a questionnaire survey. The survey is a quantitative technique that aims to achieve specific objectives by collecting data more extensively than in depth and quantitatively. The validity of 
the results will be verified if the questionnaire reflects the concepts (Bryman, 2012, p. 47). The objective was to evaluate the students' perception of their health and the way they take care of it. It was also intended to hear the existence or not of information search behaviors and information gathering, as well as to know if there are relational vectors, such as family in this health research interaction by these young people.

\section{Results}

Young people want to know about their health, but feel that they should do this research by themselves. On the other hand, health information research and use skills demonstrate a failure in both access to reliable information and processing and understanding.

We obtained 51 responses from 17 - 25 years old (Figure 1), male and female, resident in Greater Lisbon.

When asked what it meant to them to be healthy, " $84.28 \%$ responded according to the official WHO definition, i.e. they choose the option" to be healthy is to live in a good physical and mental mood, "while $19.6 \%$ replied that it is to have no complaints, such as discomfort and pain", $5.88 \%$ said that "it is the opposite of being sick".

A total of $84.28 \%$ of the sample consider that to be healthy is to live with good physical and mental disposition and not only have no diseases.

The "how often do you go to the doctor" question showed that approximately $53 \%$ go to the doctor only when they have complaints, although $11.76 \%$ reported going every 6 months. It would be important in a later study to check the reasons for this visit to the doctor twice a year. When dealing with adolescents and young people beyond any vaccination plan, it is important to check what type of health care these young people looks for twice a year.

In the evaluation made to understand which health institutions or organizations they knew, information and knowledge was dispersed by a set of institutions

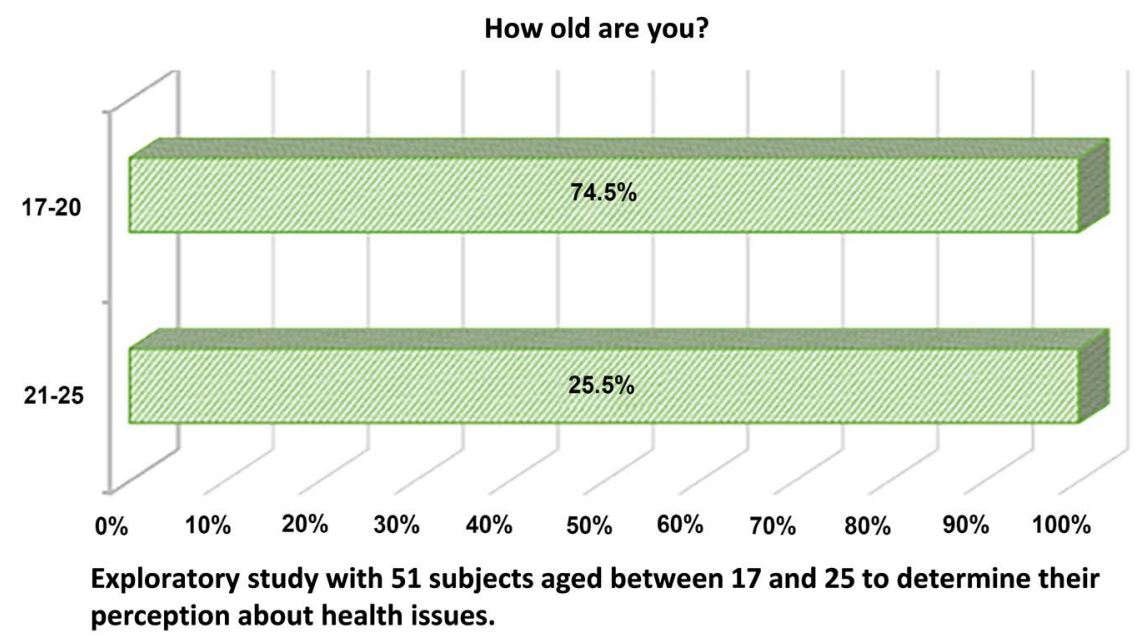

Figure 1. Percentage of ages that have answered to questionnaire. 
that, according to the order represented that a total of $25.48 \%$ knew the INEM (National Institute of Medical Emergency), 17.64\% knew the WHO (World Health Organization), the General Health System (DGS) with 15.68\%, "other" with a total of $13.72 \%$, and with $11.76 \%$, the portal of the national health system.

When asked if they feel the need to have a doctor to advise them on their health, $41.16 \%$ answered "yes" although $21.56 \%$ answered that they do not usually have questions about their own health and $21.56 \%$ chose the internet option to clarify the doubts.

To know more precisely how young people are informed about their health and reading habits, the question was: Do you read about health? Approximately $47 \%$ selected "yes" and almost $43.50 \%$ selected "rarely" and about $10 \%$ answered "no never".

In an exploratory study of 5 dozen young students, it represents almost a split in half between those who have reading habits and those who do not. It is necessary to further investigate the social determinants that may influence these reading and information research habits, one of the ways to improve the health literacy of the population.

Interestingly, although $43.50 \%$ do not have health reading habits and therefore probably use other means (digital, audiovisual) to know the medical information available to young people, the vast majority chose favorably, selecting the option that there is a lot of medical information directed to young people (43.12\%) and also feel that they have the information they need and when they need it (49\%).

Question 9 (Table 3) focused on personal concerns: To the following areas, which one deserves your most attention? Overall well-being came first with $33.32 \%$, followed by stress (19.60\%) and then healthy eating (15.68\%) and regular sport (11.76\%). Living outdoors and being informed about your health had the lowest rating, with only $3.92 \%$ choosing these two items.

Finally, the 10th question focuses on whether the young student has direct family members who are health professionals? If so, do you feel that this person/s has an influence on your general health knowledge? A total of $70.56 \%$ say

Table 3. Evaluation between well-being and stress.

\begin{tabular}{lc}
\hline (P9) To the following areas, which one deserves your most attention? & Percentage \\
\hline Overall well-being & $33.32 \%$ \\
Regular sports & $11.76 \%$ \\
Healthy eating & $15.68 \%$ \\
Sleep well and enough hours & $9.80 \%$ \\
Stress & $19.60 \%$ \\
Living Outdoor & $3.92 \%$ \\
Being informed about my health & $3.92 \%$ \\
\hline
\end{tabular}


they do not have close family members working in health care, although $21.56 \%$ say they have health care family members and they help lot to clarify my health concerns.

\section{Discussion and Conclusion}

Since the target population is part of a group of adolescents and young people, it is acceptable that they do not have a "scientific" understanding of health, i.e. that they understand health only as the absence of symptoms, while ignoring that there may be silent or slow developing diseases. Although without symptoms, are latent and may affect health.

There was some disagreement regarding the question "how often do you go to the doctor?" (P4) compared with the question "do you need a doctor to advise you on your health" (P6), because while over $50 \%$ only go to the doctor when they have complaints, $41.16 \%$ say they feel the need to have a doctor to advise. Further study will explore whether this doctor who advises them is a family doctor, a private doctor or possibly a doctor from an emergency department. Adolescence is a stage of human development marked by that occur both in the physical aspect and countless changes in the psychosocial sphere [16].

Health information is one of the most searched topics online and 8 out of 10 Internet users report having searched health information online at least once, making it the third most popular activity on the web followed by e-mail reading and using search engines as a common and frequent activity [17].

Access to e-Health information is present for all who have Internet, however, access to e-Health does not unambiguously guarantee the accuracy and truthfulness of discerning good quality health information [18].

On the other hand, the health professional who assists adolescents must know various aspects, such as attitudes, beliefs of adolescence in the family and social dynamics, as well as understand the role that will play in the care of adolescents and their families [16] [19].

It is imperative to stimulate the search for correct and appropriate information by young people through school programs, in partnership with health institutions, which aims to promote health literacy skills, namely the search for online health information [20].

Health information is available through various internet platforms, such as the Health Portal or Health General System, and there are ways to obtain it by different means (books, television, magazines, newspapers).

Coleman [21] states that the health needs of younger people are associated with "obstacles faced by young people in their search for health counseling and treatment" (p. 532), being that there are many reasons inhibiting young people to visit a doctor or factors that generate anxiety among those who visit doctor, having concerns related with confidentiality, difficulty in getting a medical consultation and a general feeling that only a few family doctors are interested in adolescents problems [21]. 
Of the $7.04 \%$ (24) who read about health, 24 answered that the internet is the method used and 2 answered that they use books; Internet; scientific articles. It is noteworthy that $43.12 \%$ respond that "rarely" reads about health. These numbers leave us the open path to untapped terrain. What strategies to develop so that young people read more about health? Does the existing information not interest them? Not appealing? The use of the ACP Health Communication Model (Assertiveness, Clarity and Positivity) is suggested [13] [14].

We also find useful in this communicative health process, to make use of the ACP health communication model not only in contact with young adolescents, but also in the communicative approach to the contents and forms of information provided: these digital, interactive platforms. should preferably have human and digital channels of contact based on language, attitudes and assertive behaviors by health professionals and those providing this digital health information, as well as the need for clarity of language, simplifying and explaining the technical jargon by language easily understood by these young people and by the positive action that is intended to be achieved, which unfolds in clear, understandable and stimulating steps.

On the other hand, information and communication technologies (ICTs) play an increasingly important role in health systems because of their potential benefits for citizens and are therefore a good way to interact with some audiences, particularly young people, who are the largest users of digital platforms [22].

Assuming that schooling is a good indicator of health literacy within the European Health Literacy Questionnaire (HLS-EU 2012) and later applied to a Portuguese sample (HLS PT 2016), it was considered that it would be useful to question the perceptions of younger people about issues related to the concept of health and its components.

If literacy generally refers to the basic skills needed to operate in society, health literacy is more complex and requires additional skills, including those needed to find, evaluate and integrate health information in a variety of contexts, and requires health-related vocabulary knowledge and a health system culture [23]. It implies that the patient accesses, understands, evaluates, interprets, uses and manages a series of elements that are part of the health context: labels, prescriptions, forms, signs, medication, package inserts, including the system navigability itself (Health literacy: Report of the Council of Scientific Affairs, 1999).

WHO (1998) understands health literacy as the cognitive skills that define an individual's ability and motivation to access, understand and use information to promote and maintain good health.

Sorensen et al. [24] and, after the results of the European Health Literacy Questionnaire (2012), both underline that health literacy relates to the development of knowledge, skills and motivations of individuals to better access, evaluate, interpret, understand and use the health system in order to make informed decisions to maintain your health throughout your life cycle. Therefore, in these definitions, there is a consensus that is the ability of the individual to act on in- 
formation [25].

Whether or not having adequate levels of literacy, having the skills to process and understand health information, and being able to make appropriate decisions with it can dictate the difference, for example, between taking appropriate or toxic therapeutic doses of drugs, or whether or not to follow the indications of health technicians [11]. Rudd et al. [12] state that health literacy may be a contributing factor to the large imparity in the quality of health care that many receive (p. 1).

With the digital and audiovisual media that are available today and entering very early in young people's lives (computers, video game consoles, mobile phones, iPads and others (Youth Observatory, 2019) it is important to understand what content or what kind of information about health can be appealing and useful. At present, health information contexts include electronic sources such as the internet and other technologies, which have enhanced their role in health consumption [10] [26], becoming the privileged sources of information of the general population.

In a characterization of the profiles of young users of social networks, Murden and Cadenasso [22] mention a study carried out in Mexico (2015), with young people aged 18 to 30 years (on the behavior of the users whom they called "spectators" (minority group, representing $22 \%$ of young people and communicating with friends and being informed) and by the "creators" (the majority of them, and representing $78 \%$ with active social life on social networks, publishing content and commenting). The authors [22], also list a set of social networking user profiles that apply to young people. They are: Ultra, Deniers, Sporadic, Virgins, Observers, Royal Peacocks, Triggers, Ghosts, Multi-Appearance, Questioners, Informant and the Insecure, each with specific characteristics (2018, pp. 19-20).

Also in Portugal, electronic information sources are a strategic resource for almost half of the population, especially for adolescents and young adults (Ministry of Health. General of Health System, 2012). These sources of health information have the potential to empower people by providing tools that help them make informed decisions, as well as opportunities for personal management of each person's health status [27].

Several authors suggest the incorporation of the internet into health intervention school programs as a way of providing opportunities to develop health literacy skills in young people, notably through teaching about the search and selection of information from electronic sources [20] [28].

Ghaddar et al. [20], in an online survey applied to a cross-sectional random sample of 261 high school students in South Texas where health literacy was assessed by eHEALS and New Vital Sign (NVS), 56\% heard of MedlinePlus ${ }^{\circledast}$ and $52 \%$ had adequate levels of health literacy associated with self-efficacy and online health information research. As a result, the authors found that exposure to a trusted source of online health information is associated with higher levels of health knowledge. 
In the qualitative study by Gray et al. [20], with twenty-six Focus group with 157 adolescent students, 11 - 19 years old, conducted in a convenience sample in high schools in various geographic and socioeconomic contexts in the United Kingdom and the United States of America between May From 2001 to May 2002, the results pointed to students' difficulties in accessing health information online. Health literacy challenges included at the functional level [29], for example, the correct spelling of medical terms and the ability to ask questions that accurately describe symptoms. Challenges at an interactive level included the appropriate use of health information to address personal health issues within their knowledge networks. Critical literacy challenges already included discerning the relevance of information that was obtained through search engines and knowing which sites to trust. Among the results obtained, there was difficulty for young people in the level of health literacy, whether functional, interactive or critical. Even as part of the health curriculum, the Internet may offer opportunities to identify these deficiencies and help build better health skills literacy among adolescents.

Before the Internet, it was difficult for non-specialist audiences to access health information because it was found mostly in medical books and magazines [17]. Since the emergence of the World Wide Web (www), referred to as the Internet, the number of health information searches online has grown remarkably. Today, the Internet represents an important source of health-related information. International studies show that up to $72 \%$ in the US [30] and up to $71 \%$ in Europe [31] of Internet users do health-related research. According to most studies, the main reasons for researching health information on the Internet are specific illnesses or health problems [30].

The literature suggests that due to the increasing dissemination and use of online health information, patients are more empowered and the doctor-patient relationship has become increasingly participatory [32].

Empirical studies have shown that informed patients are more compliant, which contributes to better health outcomes [33] [34]. In addition, health costs can be reduced because informed citizens use health services more efficiently [34]. In adolescence, doubts arise regarding a large number of situations [35] including aspects related directly or indirectly to health. Doubts include diet [36], sport [37], sexually transmitted diseases [19], hormonal changes [38], consumptions and additions [39], sleep [40], among others.

Norman and Skinner [41] point out that with the huge amount of health information on the Internet, this task requires much more ability to interpret and demonstrate than simply being able to enter a disease name or medical term into any browser, like Google or Bing. The authors [41] stress that when using the Internet as a medical education resource, consumers must reach a point of critical analysis and discriminating between primary and secondary sources of health information. In order to transmit information to young people effectively, clearly and productively, it is important to use the media that is most used by all in these younger population segments where digital information reigns [28]. 
A study by Garcia and Hansen [28] found that online access to a credible source of health information is associated with higher levels of health literacy. The inclusion of sites with credible health information in school curricula is a promising approach to promoting health literacy in young people. The simplicity of language with the simplification of desired content and associated with what effectively young adolescents consider appealing in learning, and which necessarily relates to digital platforms, may be the keys to a better understanding and adherence to these health contents.

In a wider range that bridges the gap between information research and the need for problem solving, evidence and literature show that people do not rationally process all the information that is available [42], and therefore they sometimes make "shortcuts, forms of inference that require little effort" [43]. Motivational and affective aspects must intervene as much as cognitive processes. Alvaro \& Garrido [43] highlight the interdependent nature of behavioral processes and, following Mead, Vygostsky and Bartlett, [43] (p. 261), state that "the contents of the mind are not the product of information processing, but the result of interpretative processes that have a cultural origin and that we learn in the course of social interaction". So, young people, in their various roles, students, children, friends, sportsmen, patients, have to gain from a vision of health systems that is more suited to their needs, attitudes, and understanding of the universe around them. Bandura [44] with his social cognitive perspective, highlights the important role of modeling, environmental influences, where the individual in their environment and context becomes an agent of their behavior.

The right paths seem to go through the following steps:

1) Incorporating a credible online health information resource into school health education curricula is important for promoting youth health literacy [28].

2) Sources of health literacy made available through various means and in a step-by-step manner to enable greater understanding and self-efficacy not only in young people but throughout society. Health-related activities take place in a wide variety of environments (home, work, community health institutions) and may involve a wide range of activities related to family, community, economic, leisure and safety issues. A parent measuring a child's temperature, the worker reading about correct material handling procedures, the consumer calculating the difference in salt content on the labels of two canned vegetable brands, the patient reading about dental options and the seniors filling out a health insurance form are all health-related tasks in different settings for different purposes and with different types of materials (National Academies Press, 2004).

3) Credibility of sources must be ensured. The ability to define and disseminate useful eHealth information from trusted medical sources, such as government organizations (DGS, National Institutes of Health, Centers for Disease Control and Prevention), medical institutions, and experts promoting credible information on health, making an effective comparison with opinion or unreliable announcements in value and results for the health of the individual and the population, especially for the young. 
4) Make consumers more critical in internet research, with better health education.

5) Schools should include health literacy subjects in their programs. Nowadays, some activities related to health promotion in children and young people are already in basic and secondary level schools [45].

6) Development of parenting skills, teachers, librarians and health professionals to better access, understand and use health information, in addition to the often anonymized responsibility of the "system". Teenagers and young people stand out in terms of their use of digital tools (computer use, and the web through their social networks), as they make the most use of digital platforms ([22], p. 8) but may have difficulties in various other areas of knowledge such as access, understanding and use of the information contained in these platforms and thus with deficits in health literacy.

Actual results are still far from being evaluated. Much more human investment will still be needed and understanding how adolescents and young people can access, understand and use health information for their benefit and that of their peers and family and community involvement.

\section{Ethical Clearance}

Participants data privacy and confidentiality was maintained all the time since there were no questions including personal data, such as DOB, Telephone number, email address, home address, name, affiliation, familiar history or any other kind of sensitive data.

\section{Conflicts of Interest}

The authors declare no conflicts of interest regarding the publication of this paper.

\section{References}

[1] Marcus, E.N. (2006) The Silent Epidemic-The Health effects of Illiteracy. New England Journal of Medicine, 355, 339-341. https://doi.org/10.1056/NEJMp058328

[2] Quenzel, G., Schaeffer, D. and Messer, M. (2015) Health Literacy among Less Well-Educated Young People: Influencing Factors and Consequences. Bundesgesundheitsblatt-Gesundheitsforschung-Gesundheitsschutz, 58, 951-957. https://doi.org/10.1007/s00103-015-2201-y

[3] OECD (2000) Literacy in the Information Age. Final Report of the International Adult Literacy Survey: Organisation for Economic Co-Operation Development.

[4] Simonds, S.K. (1974) Health Education as Social Policy. Health Education Monographs, 2, 1-10. https://doi.org/10.1177/10901981740020S102

[5] Ratzan, S. and Parker, R. (2000) Introduction. In Selden, C.R., Zorn, M., Ratzan, S. and Parker, R.M., Eds., Health Literacy, Current Bibliographies in Medicine 2000-1, U.S. Dept. of Health and Human Services, Public Health Service, National Institutes of Health, National Library of Medicine, Reference Section, Bethesda, 5-7.

[6] Santos, P., Sá, L., Couto, L. and Hespanhol, A. (2017) Health Literacy as a Key for Effective Preventive Medicine. Cogent Social Sciences, 3, Article ID: 1407522. 
https://doi.org/10.1080/23311886.2017.1407522

[7] Santos, P., Sá, L., Couto, L. and Hespanhol, A. (2018) Health Literacy and Equity. In: Figueiredo, G.L.A., Martins, C.H.G. and Akerman, M., Eds., Vulnerabilities \& Health: Groups on the Scene for Visibility in Urban Space, HUCITEC, 462-473.

[8] Silva, C.F., Rocha, P. and Santos, P. (2018) Consumption of Licit and Illicit Substances in Portuguese Young People: A Population-Based Cross-Sectional Study. Journal of International Medical Research, 46, 3042-3052. https://doi.org/10.1177/0300060518767588

[9] Santos, P., Sá, L., Couto, L. and Hespanhol, A. (2018) Sources of Information in Health Education: A Crosssectional Study in Portuguese University Students. $A M J$, 11, 352-360. https://doi.org/10.21767/AMJ.2018.3435

[10] Stellefson, M., Hanik, B., Chaney, B., Chaney, D., Tennant, B. and Chavarria, E.A. (2011) eHealth Literacy among College Students: A Systematic Review with Implications for eHealth Education. Journal of Medical Internet Research, 13, e102. https://doi.org/10.2196/jmir.1703

[11] Bodie, G.D. and Dutta, M.J. (2008) Understanding Health Literacy for Strategic Health Marketing: eHealth Literacy, Health Disparities, and the Digital Divide. Health Marketing Quarterly, 25, 175-203. https://doi.org/10.1080/07359680802126301

[12] Rudd, R.E., Kaphingst, K., Colton, T., Gregoire, J. and Hyde, J. (2004) Rewriting Public Health Information in Plain Language. Journal of Health Communication, 9, 195-206. https://doi.org/10.1080/10810730490447039

[13] Vaz de Almeida, C. (2016) Welcoming, Empowering, Forwarding-Health Literacy: The Paths to Greater Training for Health Professionals. Congress of the Scientific Association of Nurses (ACE) Magazine in Training, Lisbon, 12-13 May 2016, 8-15. http://www.acenfermeiros.pt/ficheiros/uploads/6011fa933c32bfb $94 \mathrm{c} 5 \mathrm{cc} 8388 \mathrm{fcb} 30 \mathrm{e} 6$ .pdf

[14] Belim, C. and Vaz de Almeida, C. (2018) Healthy Thanks to Communication: A Model of Communication Competences to Optimize Health Literacy-Assertiveness, Clear Language, and Positivity. In: Papalois, V. and Theodosopoulou, M., Eds., $O P$ timizing Health Literacy for Improved Clinical Practices, IGI Global, Hershey, 124-152. https://doi.org/10.4018/978-1-5225-4074-8.ch008

[15] Plain Writing Act of 2010 (2010) Public Law 111-274 Oct. 13, 2861-2863.

[16] Cruz, T.J. (2007) Adolescent, Family and Health Professional. Adolescents and Health, 4, 45-50.

[17] McMullan, M. (2006) Patients Using the Internet to Obtain Health Information: How This Affects the Patient-Health Professional Relationship. Patient Education \& Counseling, 63, 24-28. https://doi.org/10.1016/j.pec.2005.10.006

[18] Fox, S. (2011) Ehealth Literacy among College Students: A Systematic Review with Implications for Ehealth Education. Pew Internet \& American Life Project, Washington DC. https://www.webcitation.org/62D0se6Gu

[19] Taquette, S., Vilhena, M.M. and Paula, M.C. (2004) Sexually Transmitted Diseases in Adolescence: Study of Risk Factors. Brazilian Society Journal Tropical Medicine, 37, 210-214. https://doi.org/10.1590/S0037-86822004000300003

[20] Gray, N.J., Klein, J.D., Noyce, P.R., Sesselberg, T.S. and Cantrill, J.A. (2005) The Internet: A Window on Adolescent Health Literacy. Journal of Adolescent Health, 37, 243.e1-243.e7. https://doi.org/10.1016/j.jadohealth.2004.08.023

[21] Coleman (2001) Meeting the Health Needs of Young People. Journal of Epidemiol- 
ogy and Community Health, 55, 532-533. https://doi.org/10.1136/jech.55.8.532

[22] Murden, A. and Cadenasso, J. (2018) Being Young in the Digital Age. An Approach to the Processes of Construction of Subjectivity. CEPAL: Foundation SM.

[23] Rootman, I. (2009) Presentation at the University of Victoria, BC.

[24] Sorensen, K., Van den Broucke, S., Fullam, J., Doyle, G., Pelikan, J., Slonska, Z. and Brand, H. (2012) Health Literacy and Public Health: A Systematic Review and Integration of Definitions and Models. BMC Public Health, 12, Article No. 80. https://doi.org/10.1186/1471-2458-12-80

[25] Hinnant, A. and Len-Rios, M.E. (2009) Tacit Understandings of Health Literacy. Science Communication, 31, 84-115. https://doi.org/10.1177/1075547009335345

[26] Norman, C.D. and Skinner, H.A. (2006) Ehealth Literacy: Essential Skills for Consumer Health in a Networked World. Journal of Medical Internet Research, 8, e9. https://doi.org/10.2196/jmir.8.2.e9

[27] Austin, R. (2012) eHealth Literacy for Older Adults Part I. Ania-Caring Newsletter, 27, 7-9.

[28] Ghaddar, S.F., Valerio, M.A., Garcia, C.M. and Hansen, L. (2012) Adolescent Health Literacy: The Importance of Credible Sources for Online Health Information. Journal of School Health, 82, 28-36. https://doi.org/10.1111/j.1746-1561.2011.00664.x

[29] Nutbeam, D. (1998) Health Promotion Glossary. Health Promotion International, 13, 349-364. https://doi.org/10.1093/heapro/13.4.349

[30] Fox, S. and Duggan, M. (2013) Health Online 2013. Pew Internet \& American Life Project. https://www.pewinternet.org/2013/01/15/health-online-2013

[31] Andreassen, H.K., Bujnowska-Fedak, M.M., Chronaki, C.E., Dumitru, R.C., Pudule, I., Santana, S., et al. (2007) European Citizens' Use of E-Health Services: A Study of Seven Countries. BMC Public Health, 7, 53-60.

https://doi.org/10.1186/1471-2458-7-53

[32] Cullen, R. (2006) Health Information on the Internet. Praeger, London.

[33] Berger, T. (2009) Meet the e-Patient: Chancen und Risiken des Internets für das Verhältnis von Gesundheitsfachleuten und ihren Klienten. In: Stetina, B.U. and Kryspin-Exner, I., Eds., Gesundheit und Neue Medien, Springer, Wien, 73-83. https://doi.org/10.1007/978-3-211-72015-8 4

[34] Schmidt-Kaehler, S. (2004) Patienteninformation online. Theoretische Grundlagen, Planung und Entwicklung eines Konzeptes für die Patientenschulung im Internet. Hans Huber, Bern.

[35] Healthy People 2020 (2019) 2020 Topics \& Objectives Adolescent Health. https://www.healthypeople.gov/2020/topics-objectives/topic/Adolescent-Health

[36] Pereira, C.M., Silva, A.L. and Sá, M.I. (2015) Factors That Influence Eating Behaviors: Questionnaire on Adolescent Food Choices. Psychology, Health \& Diseases, 16, 421-438.

[37] Seabra, A.F., Mendonça, D.M., Thomis, M.A., Anjos, L.A. and Maia, J.A. (2008) Biological and Socio-Cultural Determinants Associated with Physical Activity in Adolescents. Public Health Notebook, 24, 721-736

https://www.scielosp.org/article/csp/2008.v24n4/721-736

https://doi.org/10.1590/S0102-311X2008000400002

[38] Pechanskya, F., Szobota, C.M. and Scivoletto, S. (2004) Alcohol Use among Adolescents: Concepts, Epidemiological Characteristics and Etiopathogenic Factors. Brazilian Journal of Psychiatry, 26, 14-17 http://www.scielo.br/pdf/\%0D/rbp/v26s1/a05v26s1.pdf 
[39] Camargo, E.A.I. and Ferrari, R.A.P. (2009) Adolescents: Knowledge about Sexuality before and after the Participation in Prevention Workshops. Ciência Saúde Coletiva, 14, 937-946. https://doi.org/10.1590/S1413-81232009000300030

[40] Pinto, T.R., Pinto, J.C., Pinto, H.R. and Paiva, T. (2016) Sleep in Portuguese Adolescents: Proposal for a Three-Dimensional Model. Psychological Analysis, 34, 339-352.

[41] Norman, C.D. and Skinner, H.A. (2006) eHEALS: The eHealth Literacy Scale. Journal of Medical Internet Research, 8, e27. https://doi.org/10.2196/jmir.8.4.e27

[42] Tversky, A. and Kahneman, D. (1973) Judgment under Uncertainty: Heuristics and Biases. Science, 185, 1124-1131. https://doi.org/10.1126/science.185.4157.1124

[43] Garrido, A. (2006) Health Psychology: Theory, Intervention and Research. 256.

[44] Bandura, A. (1986) Social Foundations of Thought and Action: A Social Cognitive Theory.

[45] PAPES (2014) Health Promotion and Education Support Program. General Department for Education. 